\section{ralud mental}

Díaz Gómez, José Luis

La naturaleza de la lengua

Salud Mental, vol. 38, núm. 1, enero-febrero, 2015, pp. 5-14

Instituto Nacional de Psiquiatría Ramón de la Fuente Muñiz

Distrito Federal, México

Disponible en: http://www.redalyc.org/articulo.oa?id=58238799002

- Cómo citar el artículo

- Número completo

- Más información del artículo

- Página de la revista en redalyc.org
Salud Mental

ISSN: 0185-3325

perezrh@imp.edu.mx

Instituto Nacional de Psiquiatría Ramón

de la Fuente Muñiz

México 


\title{
La naturaleza de la lengua*
}

\author{
José Luis Díaz Gómez
}

Conferencia magistral

\section{SUMMARY}

The present discourse of admission to the Mexican Academy of Language traces the biological foundations of human language in animal behavior, hominization, and neuroscience.

Animal intentional and symbolic expressions constitute evident foundations of human propositional language and thought. Through arduous training, individual parrots and apes learn, recognize, and express abstract symbols, while vervet monkeys in their natural habitat produce different cries to identify their predators. A communicative intention is furthermore suggested by social play, tactic deception, machiavellic intelligence, or calls to name individuals. Such capacities evolved toward Homo sapiens and its early pictorial representations show adaptive and innovative symbolic talents based on neuronal networks that generate cognitive resources in coordination with the environment.

Right-hand skills, tool production, symbolic language, and left hemisphere predominance constitute associated capacities emerging during the human split from the apes 2.5 million years ago. Even though the modularity of language engages specialized brain areas for expression and comprehension, meaning requires a wider connectivity. Processing verbal information involves the activations of neural networks genetically-disposed in a brain device that is conditioned by repetitive learning. Linguistic representation utilizes firing codes of neurons organized in such networks; their contents are determined by the origin and destiny of the neural pathways, while meanings emerge from the dynamic patterned process of the interconnections among brain modules. The human symbolic realm is detectable in the world of expression and culture because it is mediated by social processes tangled to brain processes through appropriate practices. Meaning is thereby conceived as a dynamic braid with an external or cultural loop, and an internal or neurosemantic loop.

The nascent contribution of biological, cognitive and brain sciences in coordination to humanistic disciplines to understand the nature of language is as revealing as it is challenging.

Key words: Language, communication, neuropsychology, culture.

\section{RESUMEN}

El presente texto de ingreso a la Academia Mexicana de la Lengua perfila los fundamentos biológicos del lenguaje y el significado en la conducta animal, la hominización y la neurociencia.

Las expresiones intencionales y simbólicas en animales constituyen claros cimientos del lenguaje y el pensamiento proposicional humano. Mediante entrenamiento, ejemplares de aves y simios aprenden, reconocen y expresan símbolos abstractos, en tanto que los monos verdes en su medio natural emiten diferentes voces para identificar a sus predadores. La intención comunicativa está además sugerida por el juego social, el engaño táctico, la inteligencia maquiavélica o los silbidos para nombrar individuos. Dichas habilidades evolucionaron hasta el Homo sapiens cuyas representaciones pictóricas iniciales marcan una simbolización adaptativa basada en circuitos neuronales que generan recursos cognoscitivos en coordinación con el medio.

La destreza derecha, la fabricación de herramientas, el lenguaje simbólico y la predominancia del hemisferio izquierdo son capacidades engarzadas que emergieron durante la escisión humana de los simios. Si bien la modularidad del lenguaje implica zonas especializadas para su expresión y comprensión, el significado requiere de una amplia conectividad. Procesar información verbal requiere la activación de redes genéticamente dispuestas en un dispositivo cerebral que se acondiciona por aprendizaje repetitivo. La representación lingǘstica utiliza códigos de disparo de neuronas organizadas en dichas redes cuyos contenidos están determinados por el origen y destino de las vías, en tanto que el significado surge de la pauta dinámica de las interconexiones entre los módulos. El ámbito simbólico humano está la vista en el mundo de la expresión y la cultura pues está mediado por procesos sociales acoplados a procesos cerebrales mediante una práctica. El significado tiene así un asa externa o cultural un asa interna o neurosemántica.

La contribución de las ciencias biológicas, cognitivas y cerebrales coordinadas con las humanidades para comprender la naturaleza de la lengua es tan reveladora como desafiante.

Palabras clave: Lenguaje, comunicación, neuropsicología, cultura.

Departamento de Historia y Filosofía de la Medicina. Facultad de Médicina. UNAM.

Miembro del Comité Editorial de SALUD MENTAL. E-mail: jldiaz43@gmail.com

* Discurso de Ingreso a la Academia Mexicana de la Lengua, 12 de junio de 2014 


\begin{abstract}
Y escribo... escribo ¿para qué? ¡Volved
A lo más hondo del alma

Tempestuosas imágenes!

Id a morar con los muertos recuerdos:

Que la mano temblorosa en el papel sólo escriba

¡Palabras, y palabras, y palabras!

¿De la idea la forma inmaculada y pura

Dónde quedó velada?

Rosalía de Castro

(Fragmento del poema ¡Silencio! publicado en Follas Novas, 1880)
\end{abstract}

\section{INFORMACIÓN, COMUNICACIÓN, LENGUAJE}

La lengua no se limita a la palabra, al enunciado o al argumento; se asienta y engarza con múltiples lenguajes disponibles gracias a la evolución de los seres vivientes, a la fisiología del cerebro y a los sistemas perceptuales y expresivos del cuerpo. Hay comunicación y lenguaje en el gesto y el aroma, en la música y en el lienzo, en el mapa y en el edificio. Se atribuye un lenguaje bioquímico a los ecosistemas por el cual las plantas atraen al polinizador que las propaga o disuaden al defoliador capaz de arrasarlas. En El origen del hombre Charles Darwin deliberó que los cantos emitidos por las aves constituyen la analogía biológica más cercana al lenguaje humano y por esta razón los consideró un "protolenguaje" favorecido evolutivamente mediante el mecanismo de selección sexual. ${ }^{1}$

La selección sexual implicaría que el rasgo se presentaría sólo en los machos, pero se ha demostrado la existencia de canto en hembras en muchas especies de aves. A pesar de esta inexactitud, es aún posible sostener la noción de Darwin sobre el fraseo del canto del pájaro como un heraldo a partir del cual se hayan seleccionado elementos del habla y la música, pero por otros mecanismos evolutivos que aún no se dilucidan. A partir de diversos análisis de la comunicación animal, unos investigadores del Instituto Tecnológico de Massachusetts ${ }^{2}$ sostienen que el canto de los pájaros se asemeja al aspecto expresivo de las frases humanas (el cual admite variaciones), en tanto que la comunicación de las abejas o las vocalizaciones de los primates se parecen más al aspecto léxico que mantiene la estructura básica (como sujeto, verbo y predicado) de la lengua humana. Especulan entonces que hace unos 80 mil años en los humanos se fusionaron estas dos aptitudes para engendrar el lenguaje en su dimensión actual.

Siguiendo las directrices teóricas de Darwin en referencia al valor adaptativo de la conducta animal, el etólogo y premio Nobel Konrad Lorenz encontró fundamentos de diálogo en los rituales de cortejo o agresión que realizan muchas especies de aves. ${ }^{3}$

\footnotetext{
'Darwin Ch. (1871). The descent of man and selection in relation to sex. Londres: John Murray Traducido como: El origen del hombre por Joan Domenec Ros para Crítica (Barcelona, 2009). Para una revisión más actual del tema véase: Doupe AJ, Kuhl PK (1999). Birdsong and human speech: Common themes and mechanisms. Annual Review Neuroscience. 22:567-631.

2 Miyagawa S, Berwick RC, Okanoya K. The emergence of hierarchical structure in human language. Frontiers Psychology 2013. DOI: 10.3389/fpsyg. 2013.00071 .
}

Más rotundamente se manifiestan elementos del habla en los cantos de la yubarta o ballena jorobada (Megaptera novaeangliae) que, en secuencias coherentes de notas compartidas, le permite cazar en grupo bancos enteros de peces mediante una red de burbujas generada coordinadamente entre muchos individuos. ${ }^{4}$

La etología cognitiva detecta inicios aún más cercanos en tres gritos distintos de alarma que profiere el mono verde en la sabana de África para alertar a su tropa sobre la aparición de predadores, como se verá más adelante. Comprendemos entonces que el lenguaje no sólo es una construcción cultural, sino que se fundamenta en capacidades de comunicación que compartimos con otras especies animales. Así, lejos de separarlos de la naturaleza por la facultad del lenguaje, estas evidencias crecientes vinculan a los seres humanos reciamente a ella, pues los coloca en el centro de un profuso contorno natural de información y comunicación. ${ }^{5}$

$\mathrm{Al}$ tiempo que reconocemos este vínculo semiótico con las criaturas del mundo, también damos cuenta de las diferencias que transcurren desde la vastedad de la información inmanente a la estructura del cosmos, pasando por la elaborada comunicación animal, para llegar a la expresión intencional y simbólica del lenguaje verbal humano. Solicito al escucha o al lector imaginar tres círculos concéntricos uno dentro de otro, como el blanco de un arquero. Sea el mayor y más externo el mundo de la información, la red de formas y señales que se manifiesta desde la telaraña que mantiene la estructura de los súper cúmulos de galaxias, hasta la instrucción que expresa el DNA para determinar la forma y las funciones de cada célula. Este es un mundo de información que permea la estructura del cosmos como un adherente casi inmaterial.

Ahora bien, dentro de este colosal universo de información, se ubica el círculo más acotado de la comunicación, donde la información transcurre en forma de señales producidas por un emisor y decodificadas por un receptor. Esta es carac-

3 Una de las últimas obras traducidas de Lorenz es Estoy aquí ¿Dónde estás tú?
(Traducción de Manuel Vázquez. Barcelona: Plaza \& Janes, 1989) en la que,
con la colaboración de Michael Marlys y Angelika Tipler, comenta ampliamen-
te sus investigaciones durante más de cinco décadas sobre la conducta del
ganso gris. El título implica el significado comunicativo del graznido justificado
mediante detalladas observaciones etológicas.
4 Wiley D, Ware C, Bocconcelli A, Cholewiak D, Friedlaender A, Thompson M,
Weinrich M (201 1) Underwater components of humpback whale bubble-net fee-
ding behavior. Behaviour 148 (5): 575 DOl: $10.1163 / 000579511$ X570893.
5 Para mayor información sobre las bases etológicas del lenguaje humano véa-
se: Del gesto a la palabra: la etología de la comunicación en los seres vivos de
Boris Cyrulnik. Traducción de Marta Pino Moreno. Barcelona: Gedisa; 2004 . 
terística crucial de la vida terrestre, pues los vivientes son exquisitamente sensibles a las señales que les son significativas y las discriminan sobre un fondo de "ruido". La detección de los estímulos caracteriza la sensibilidad de la materia viva y la provee no sólo de activación y respuesta, sino de sentido, pues su réplica al medio ambiente tiene dirección y objetivo, factor indispensable de la evolución. La vida entraña comunicación en el interior de cada célula, entre tejidos, órganos y sistemas, entre el organismo y su nicho o entre individuos mediante mensajes químicos o físicos y eventualmente semánticos y simbólicos. En el libro La sabiduría del cuerpo, de 1932, el eminente fisiólogo Walter Cannon ${ }^{6}$ había discernido que la cooperación funcional de tejidos distantes a través de señales nerviosas y moleculares provee al organismo de una especie de inteligencia flotante reflejada en la homeostasis. ${ }^{7}$ Estos enjambres funcionales y densamente imbricados del cuerpo son semióticos porque constituyen redes organizadas de señales que pueden llegar a constituir significados cuando se enlazan con el mundo en tramas simbólicas.

Finalmente, en el centro de este círculo de comunicación se ubica la diana del lenguaje hablado, definida por el valor simbólico de las señales. A diferencia del círculo anterior, la palabra es rótulo que permite la recreación, el manejo y la transmisión de información en ausencia del objeto denominado, una proeza evolutiva que requiere de significación, memoria, imaginación, representación o intención, facultades cognoscitivas que facilitan la acción de pensar y comunicar el pensamiento. El lenguaje es un sector restringido aunque culminante de la comunicación pues involucra señales cuyo contenido ya no está en relación directa con su constitución física. La capacidad lingüística aumenta en órdenes de magnitud la información que es posible procesar y transmitir, pues mediante actos de habla y comprensión los emisores y receptores del lenguaje comparten representaciones y saberes, tal y como acontece en este momento. Así, conforme nos acercamos de la periferia al centro de los círculos concéntricos, los estratos que separan a la información de la comunicación y a ésta del habla están marcados por una condensación de mensajes y al mismo tiempo de conocimiento y de conciencia que permiten, en un juego de espejos, concebir a la información, a la comunicación y al propio diagrama imaginario que acabamos de invocar.

Conviene distinguir una conciencia básica, la capacidad de sentir, de la extendida y de más alto orden, la capacidad de saber. Los seres sintientes, la mayoría de los vivientes móviles, son capaces de sentir pues muestran excitabilidad, sensibilidad y sentido, en tanto que los sentientes, los encefalizados, agregan la facultad de saber y expresan señalización, cognición, mapeo, memoria y representación. Es posi-

\footnotetext{
${ }^{6}$ Wisdom of the body en 1932. Traducido por Augusto Pi Suñer y publicado en castellano por Editorial Séneca en 1941.

7 Este importante concepto fue acuñado por el propio Cannon y luego aplicado por la cibernética a los sistemas cuyo control del equilibrio se alcanza mediante flujos de retro-información presentes en los ecosistemas, la biosfera (hipótesis de Gaia) o las estructuras sociales, entre otros.
}

ble discernir más finamente entre un saber no proposicional, cuando la representación no está codificada en forma de lenguaje y un saber proposicional recopilado en un sistema simbólico que finalmente permite la autoconciencia semántica: ese saber que sabe de sí. En tanto se considera un sistema de signos o sonidos articulados que permiten la comunicación de estados mentales, el habla involucra al oído y a la cavidad bucofaríngea, en particular a la lengua, órgano y metáfora universal del lenguaje. Pero sucede que el lenguaje es algo más que hablar y comprender locuciones, es una interacción retórica múltiple que involucra actores, distancias, voces, tonos o gestos, actos del habla ${ }^{8}$ que ocurren en un contexto social pletórico no sólo de normas de interacción, sino de cosmovisiones derivadas y moduladoras del lenguaje.

Pero, como bien lo estableció Ferdinand de Saussure en $1916,{ }^{9}$ el meollo de toda lengua es el significado, entendido como el contenido mental que se da a un signo o significante. ¿Cómo se estipula y se comprende el significado de una palabra, de una locución? He aquí el meollo de la semántica.

Por un largo periodo se consideró el significado como la asociación entre un concepto y una imagen mental: la palabra caballo genera en la mente de un hablante de español la imagen de un vertebrado de ciertas características y esa imagen constituiría el significado. Sin embargo a finales del siglo XIX el matemático y filósofo Gottlob Frege aseveró que el significado no es una simple asociación mental y privada entre una imagen y una palabra, pues la referencia y el sentido, que según su teoría conforman el significado, rebasan al individuo. ${ }^{10}$ En los años 1930, el psicólogo soviético Lev Vygotsky consideró a la palabra como sustituto convencional de la acción de señalar, en la que el significante sería el dedo índice y el significado el objeto indicado. ${ }^{11}$ De manera más célebre, Ludwig Wittgenstein planteó que el significado de una palabra está en su uso. ${ }^{12}$ Por su parte, Hilary Putnam, en un ensayo de 1975 titulado The meaning of 'meaning' (el significado del 'significado'), ${ }^{13}$ también adopta una posición externalista en el sentido de que el significado no sólo está en la cabeza, sino en el mundo circundante. Si alguien dice "hay agua en ese vaso" y los oyentes entienden la frase, esto indica que todos ellos, el que habla y quienes le escuchan, en cualquier tiempo y lugar, tienen la misma noción de lo que hay en el vaso: algo externo a la lengua determina el significado de una palabra.

\footnotetext{
${ }^{8}$ John Searle (2001). Actos de habla, Editorial Cátedra.

9 En su Curso de lingüística general publicado póstumamente. La versión en castellano está publicada por la editorial Payot (1995).

10 Véase "Sobre el sentido y la referencia" en Estudios sobre semántica, traducción de Ulises Moulines. Barcelona; Ediciones Orbis; 1962.

11 En: Pensamiento y lenguaje, traducido por María Margarita Rotger. Ed. La Pléyade, Buenos Aires, 1987

12 Véase Investigaciones filosóficas, traducido por A. García Suárez y C. Ulises Moulines. Instituto de Investigaciones Filosóficas (UNAM) y Crítica, México, 1988.
13 "The meaning of 'meaning'", incluido en Language, Mind and Knowledge (Minnesota Studies in the Philosophy of Science, vol. 7, ed. Keith Gunderson, Minneapolis: University of Minnesota Press, 1975, pp. 131-193). Fue traducido al español como El significado de "significado" en la revista Teorema vol. XIV/3-4. El ingenioso título había aparecido décadas antes en un célebre ensayo The meaning of meaning de 1923 firmado por el lingüista Charles Ogden y el crítico literario lvor Armstrong Richards quienes propusieron el estudio del significado como una labor interdisciplinaria que originalmente incluía a la semántica y la psicología. Este libro fue traducido al castellano como El significado del significado, Paidós, Buenos Aires, 1964.
} 
Estas son aportaciones trascendentales en el sentido de que el empleo de una palabra y sus múltiples vínculos sociales son elementos contextuales necesarios para estipular el significado -el asa externa de la lengua- pero no parecen suficientes, pues es preciso que ocurra la asociación de un concepto con una señal acústica: el asa interna de la lengua. Esta asociación es algo intrínseco del pensamiento, facultad que permite la aprehensión del significado convencional de un signo lingüístico, lo que se denomina el contenido de una locución. Charles Peirce había formulado, a finales del siglo XIX, un adecuado triángulo de relaciones semióticas entre un referente (objeto, realidad), un signo (palabra, significante) y el proceso mental específico (concepto) que están implicados en el lenguaje. Subraya así la íntima conexión entre pensamiento y lenguaje pues al pensar somos conscientes de algún sentimiento, imagen, concepción o cualquier representación que funciona como un signo: ${ }^{14}$ ¿cómo ocurre este portento?

Los sentidos permiten a una criatura adquirir ciertas características de un objeto: color, tamaño, forma, sabor, olor, textura, peso. La organización de estos datos se constituye en una unidad cognitiva que abstrae características esenciales del objeto, lo cual lleva a la formación de un concepto no proposicional. Pero cuando el concepto se asocia a una palabra, a un nombre, adquiere propiedades sorprendentes pues, mediante una abstracción, se establece una conexión causal mediada en una comunidad de hablantes. ${ }^{15}$ De manera no bien comprendida, la palabra proporciona un acceso mental o insight a la naturaleza de lo que signa y así se puede entender lo que quiso decir Borges al afirmar que "en las letras de 'rosa' está la rosa", ${ }^{16} \mathrm{o}$ Umberto Eco con el críptico título de El nombre de la rosa.

Además, el concepto entraña grados de comprensión que permiten concretar, categorizar y clasificar otros conceptos, pues el significado no reside en un término por sí mismo, sino en la red de sentidos que establece con otros en ese metódico y maleable archivo que es la memoria semántica. El neuropsicólogo ruso Alexander Luria consideró a la palabra como una red de conexiones y relaciones potenciales a las que remite un objeto. ${ }^{17}$ Aún más extraordinario es el hecho de que un acto verbal del lenguaje, como el enunciado de una frase, pueda ser considerado verdadero o falso según se encuentre o no en conformidad con los hechos del mundo, lo cual es uno de los temas más espinosos de la filosofía del lenguaje, plenamente anticipado por John Locke. ${ }^{18}$

\footnotetext{
14 Véase "El ícono, el signo y el símbolo" (Traducción al castellano de Sara Barrena): http://www.unav.es/gep/IconolndiceSimbolo.html

15 El concepto se establece en gran medida gracias a un nombre. En la propuesta de Saul Kripke el nombre es un designador que se refiere a un objeto. Cuando se refiere a la misma entidad en todos los mundos posibles en los que la entidad existe, lo denomina designador rígido. Véase Saul Kripke (1978) Identidad y necesidad. Traducción de Margarita M. Valdés. México: UNAM. 16 Entidad y necesidad. Traducción de Margarita M. "Valdés. México: UNAM.
$1{ }^{\prime}$ la estrofa de "El golem", que dice así: "Si (como afirma el griego en el Cratilo)/ el nombre es arquetipo de la cosa/ en las letras de 'rosa' está la rosa/ y todo el Nilo en la palabra 'Nilo'".

17 Conciencia y lenguaje. Traducción: Marta Shuare. Madrid: Visor Libros, 1984. Luria examina las características e implicaciones de los campos semánticos, conjuntos de términos relacionados que proporcionan significados más

precisos a sus componentes (páginas 37 y siguientes).
8 En el capítulo XXXII "De las ideas verdaderas y falsas" en el Libro II del Ensayo sobre el entendimiento humano (1690), México, Fondo de Cultura
}

Hasta este momento, al sondear la naturaleza de la lengua, he vinculado la etología con la semántica. Propongo ahora avanzar por dos rutas de las ciencias naturales: la evolución de la comunicación, bosquejada ya con ejemplos de la etología, y la neurociencia del lenguaje y el significado.

\section{LA EVOLUCIÓN DEL SABER}

Vale la pena referir a dos individuos de especies distantes que han mostrado notorias habilidades de categorización y expresión semántica y aritmética: un loro gris llamado Alex (Psittacus erithacus) y un bonobo de nombre Kanzi (Pan paniscus), quienes, ${ }^{19}$ mediante ingenioso $\mathrm{u}$ arduo entrenamiento, han sido capaces de aprender y reconocer símbolos abstractos. Alex respondía a preguntas verbales de Irene Pepperberg ${ }^{20}$ sobre objetos presentes y Kanzi interactuaba con Sue Savage-Rumbaugh, mediante un tablero lexicográfico con más de 300 símbolos y obedecía órdenes verbales complejas sin mediación de gestos..$^{21}$ Alex desarrolló un vocabulario de unas 100 palabras, identificaba 50 objetos distintos, reconocía hasta siete cantidades, siete colores y cinco formas; entendía la diferencia entre pequeño y grande, igual y diferente, abajo y arriba. Mediante una orden verbal podía identificar y escoger correctamente un objeto cuadrado y amarillo entre otros de diferentes formas y colores. Alex y Kanzi no solo repetían como loros o imitaban como monos sino que procedían con la razón y la abstracción, pues las dedicadas investigadoras demostraron que eran capaces de identificar, elegir y manejar palabras, frases y objetos. ${ }^{22}$ Ahora bien: ¿para qué sirven en el hábitat natural estas capacidades lingüísticas reveladas en el laboratorio?

Los monos verdes de la sabana de África (Cercopitecus aethiops) emiten un grito particular al divisar un leopardo. Cuando escuchan esta voz los otros monos trepan velozmente a los árboles. Si aparece un águila, el mono avizor produce un llamado de alarma diferente y los oyentes miran hacia arriba mientras se esconden entre arbustos. Finalmente cuando alguno localiza a una serpiente emite un tercer aullido y los escuchas adoptan una posición bípeda y escrutan el suelo. Estas conductas diferentes ocurren igual en ausencia del depredador mediante la reproducción sonora de cada uno de los gritos previamente grabados. ${ }^{23}$

Económica, 1956. Traducción castellana de Edmundo O'Gorman, cuarto ocupante de la silla VI de la Academia Mexicana de la Lengua.

19 La cursiva aquí es intencionada.

20 Irene Pepperberg (1998). Hablando con Alex: Lógica y conversación en loros. Scientific American, 18 de mayo de 1998.

21 Par Segerdahl, William Fields y Sue Savage-Rumbaugh (2006) Kanzi's primal language. The cultural iniciation of primates into language. Palgrave Macmillan.

22 Una evaluación histórica y filosófica del lenguaje aprendido de los simios se encuentra en "Problemas en torno al lenguaje de los póngidos" de Jorge Martínez Contreras. En: Una mirada múltiple sobre el lenguaje (Víctor Manuel Alzaraz, coordinador) pp 135-159. Guadalajara, México: Universidad de Guadalajara.

${ }^{23}$ Dorothy L. Cheney, Robert M. Seyfarth (1998) How Monkeys See the World: Inside the Mind of Another Species, University of Chicago. De los mismos autores y en castellano véase: "Mente y significado en los monos" en Investigación y Ciencia, temas 32: La conducta de los primates, pp 56-63, 2003 
Ahora bien, para considerar estas vocalizaciones como palabras sería necesario determinar si la voz está precedida por una intención o deseo de avisar, pues aunque los monos verdes ostensiblemente clasifican las tres vocalizaciones de acuerdo a los objetos que denotan, quizás el emisor no tiene idea del estado mental de su audiencia y rotula un estímulo sin tener la autoconciencia y la heteroconciencia o alteridad que presupone el lenguaje humano que implica una intención comunicativa. La capacidad para inferir emociones, intenciones o motivaciones ajenas es lo que constituye la llamada, de manera quizás poco afortunada, "teoría de la mente"24 y existen indicadores en múltiples especies de esta capacidad, como son el juego social, el engaño táctico o la llamada inteligencia maquiavélica en los chimpancés y sus intrincadas estrategias sociales que han sido calificadas de políticas por el destacado etólogo contemporáneo Frans de Waal. ${ }^{25}$

Otras conductas sugieren simbolización ritual en chimpancés y en bonobos. ${ }^{26}$ Estas incluyen "rituales funerarios" (comportamientos inusuales, enfáticos, dirigidos e iterativos en referencia al cadáver de un congénere), la "danza de la lluvia" (movimientos rítmicos peculiares en el momento del inicio de las primeras lluvias de la temporada o ante una cascada), el "juego con muñecas" (la adopción de un objeto al que se trata como a un infante por parte de hembras chimpancés juveniles) y la "conducta de señalar" (la dirección de la mano o del índice para llamar la atención de congéneres hacia un objeto particular y distante que, como ya indicamos, Lev Vygotsky consideró el meollo del lenguaje).

En 1982 Nicholas Humphrey propuso que el origen de la conciencia humana dependió crucialmente de la capacidad para atribuir y compartir experiencias en los simios y los homínidos, en especial aquellos que vivían en grupos y dependían de ellos para sobrevivir. ${ }^{27}$ Robin Dunbar postula que los cerebros voluminosos y las habilidades cognitivas de los humanos han evolucionado mediante intensa competencia y estrategias sociales crecientemente elaboradas. ${ }^{28}$

La aparición hace unos 70 mil años en grupos ya globalmente distribuidos de Homo sapiens de representaciones externas en petroglifos, en pinturas rupestres o en instrumentos musicales marca una simbolización y comunicación abstracta cuya relación directa con el desarrollo del lóbulo frontal del cerebro ha sido repetidamente subrayada..$^{29}$ Roger Bartra (2007) propone a estas manifestaciones simbólicas externas,

\footnotetext{
${ }^{24}$ En un experimento clásico, a una chimpancé llamada Sarah se le mostraron fotos de una persona en una jaula y en diferentes situaciones para poder o no alcanzar un plátano fuera de la jaula. Si acaso la chimpancé se puede poner en el lugar de esta persona, debe señalar cuál es la fotografía con la posibilidad de alcanzar el plátano. Sarah pasó satisfactoriamente la prueba. David Premack y Guy Woodruff (1978): Does the chimpanzee have a theory of mind? Behavioral and Brain Sciencies, I, 515-526.

25 Véase de su autoría Primates y filósofos traducido por Vanesa Casanova. Editorial Paidós, 2007.

26 James B. Harrod (201 1) A Trans-Species Definition of Religion. Journal for the Study of Religion, Nature and Culture 1749-4907 doi:10.1558/isrnc. v5i3.327.

${ }^{27}$ Nicholas Humphrey (2001) La mirada interior. Madrid: Alianza Editorial.

28 Robin Dunbar (1997) Grooming, Gossip and the Evolution of Language. Harvard University Press.

29 Véase Dunbar, op cit.
}

que denomina prótesis cultural o exocerebro, como un recurso evolutivo de la conciencia humana. ${ }^{30}$ Julian Jaynes había argumentado en 1976 sobre el origen reciente de la conciencia humana con el requerimiento del lenguaje para la memoria episódica y especialmente con la lectoescritura. ${ }^{31}$ En ambos casos se trata de la conciencia sentiente, pues el sentir y el sentido propios de la conciencia sintiente son de origen mucho más remoto en la evolución de las especies.

Los más antiguos indicios de expresión simbólica humana han sido hallados en los grabados de la gruta Blombos en Sudáfrica, que datan de hace 77 mil años. Los petroglifos posteriores presentan claras señales de conciencia sentiente porque ostentan animales pintados de memoria, máscaras que revelan representación o simulacro y figuras humanas que parecen organizar una narrativa. Este tipo de representaciones se pueden considerar adaptativas pues están basadas en circuitos neuronales que generan recursos cognitivos en coordinación con el medio. ${ }^{32}$ La evidencia arqueológica, histórica y etnográfica indica que los sistemas culturales humanos han tenido un alto grado de evolución convergente, pues los complejos jerárquicos y ceremoniales que rodean a las clases dirigentes, el uso de minerales escasos en forma de joyas, las pirámides con cámaras funerarias y muchos otros elementos comunes entre civilizaciones lejanas y desligadas muestran una convergencia cultural que incluye símbolos como el axis mundi, el mandala y muchos otros. En adición al materialismo cultural, que postula una base práctica, eficiente y útil de los caracteres convergentes entre las culturas, ${ }^{33}$ habría que sustentar una necesidad cognitiva-afectiva-imaginativa, a veces designada como espiritual, para explicar la convergencia simbólica. Ésta debe fundamentarse en una tendencia de atribuir significado a los objetos naturales a través de una comunicación que ha dado origen a contenidos conscientes grupales y a manifestaciones estéticas. La convergencia simbólica supone que ciertos significados, emociones, valores y motivos para la acción son co-creados por individuos que intentan dar sentido a una experiencia común y se manifiestan en la construcción de imaginarios y retóricas sociales mediante una interacción cohesiva. ${ }^{34}$ Esto sucede con la música o con el lenguaje, que tienen elementos evolutivos y cognitivos comunes para la especie, pero que se revisten de la lengua o de las manifestaciones particulares a los que el individuo está expuesto en su desarrollo.

En su Human Universals, de 1991, el antropólogo Donald Brown $^{35}$ revisó una serie de investigaciones comparativas

\footnotetext{
30 Roger Bartra (2007) Antropología del cerebro. La conciencia y los sistemas simbólicos. México: Fondo de Cultura Económica.

31 Julian Jaynes (1976) The Origin of Consciousness in the Breakdown of the Bicameral Mind. Toronto: University of Toronto Press. Traducción de Agustín Bárcena: El Origen de la Conciencia en la Ruptura de la Mente Bicameral. México: Fondo de Cultura Económica, 1987.

32 Peggy La Cerra y Roger Bingham (2002) The Origin of Minds. Evolution, Uniqueness and the New Science of the Self. New York: Harmony Books. ${ }^{33}$ Marvin Harris (1987) El materialismo cultural. Madrid: Alianza Editorial.

${ }^{34}$ Ernst G. Bormann (1985) Symbolic Convergence Theory: A Communication

Formulation. Journal of Communication 35(4):128-138.

35 Donald E. Brown (1991) Human Universals. New York: McGraw-Hill.
} 
entre culturas diversas para mostrar que todas las lenguas y culturas humanas expresan metáforas, personifican fenómenos externos, califican un territorio conocido como hogareño, cocinan, proscriben el incesto y la violencia intragrupo, practican la adivinación, realizan juegos competitivos, etc. Entre estos universales el que más interesa al tema de la naturaleza de la lengua es la capacidad metafórica y simbólica del cerebro humano, lo cual conduce a la neurociencia del lenguaje.

\section{CEREBRO Y LENGUA}

La historia de la base cerebral del lenguaje se inició en 1861, cuando Pierre Paul Broca acudió a un congreso de la Sociedad Antropológica de París para mostrar el cerebro de un enfermo que había muerto con afasia y a quien llamaban Tan porque ésta era la única sílaba que podía pronunciar. El cerebro de Tan tenía una lesión circunscrita al pie de la primera circunvolución frontal del hemisferio izquierdo. Esta región es llamada hasta hoy zona de Broca y es crucial para hablar y articular el lenguaje, incluso el de signos.

La modularidad del lenguaje ${ }^{36}$ se reafirmó unos años más tarde con el descubrimiento de la zona de Wernike para la comprensión del lenguaje, convenientemente situada en la primera circunvolución temporal izquierda justo atrás de la zona de recepción auditiva. Las dos áreas están unidas por un grueso haz de fibras, llamado fascículo arqueado o arcuato, ${ }^{37}$ y trabajan en estrecha relación. La lateralización izquierda es manifiesta para la gramática y el vocabulario, pero el mapa actual del cerebro lingüístico es más bilateral e indicativo de una especialización hemisférica complementaria, pues las facultades pragmáticas, connotativas y afectivas del lenguaje, como la prosodia, la acentuación y la connotación involucran actividad del hemisferio derecho y la lectoescritura requiere de la participación de múltiples zonas sensoriales, motoras, afectivas y volitivas de los dos hemisferios. ${ }^{38}$

La preferencia para usar una mano en tareas motoras finas y la lateralización cerebral de las funciones gramaticales y semánticas son dos hechos asociados y distintivos de los humanos, cuya dominancia para el lenguaje y la pericia de

${ }^{36}$ La tesis de la modularidad cerebral, la especialización funcional de sus áreas, núcleos y regiones, se ha extendido a los procesos mentales, particularmente en La modularidad de la mente de Jerry Fodor (Traducción al castellano en: Madrid, Morata, 1986).

37 En comparación con los otros primates, los humanos tienen un fascículo arcuato más voluminoso, lo que sugiere que ha tenido un papel importante en la evolución más reciente del lenguaje. http://lenguaje-comunicacion.com/elfasciculo-arcuato-y-el-aprendizaje-de-la-palabra-una-critica/

${ }_{38}$ Para una revisión en castellano de los centros cerebrales involucrados en el lenguaje, véase: Feggy Ostrosky-Solís y Alfredo Ardila (1994) Cerebro y Lenguaje. Perspectivas en la organización cerebral del lenguaje y de los procesos cognoscitivos. México: Editoria Trillas. Una extensa revisión con más de 430 mediante imágenes funcionales del cerebro puede encontrarse en: Renewal of the Neurophysiology of Language: Functional Neuroimaging de Jean-Francois Démonet, Guillaume Thierry y Dominique Cardebat publicado en Physiological Reviews (enero de 2005) 85(1)49-95; DOI: 10.1152/physrev.00049. Se han descrito conexiones ventrales y dorsales del núcleo arcuato, tanto derechas como izquierdas que cumplen diferentes funciones en la actividad del lenguaje (Price C.J. 2000: The anatomy of language: contributions from functional neuroimaging. Journal of Anatomy. 2000;197(Pt 3):335-359). la mano derecha compromete especialmente al hemisferio izquierdo en un $90 \%$ de la población. La destreza derecha, ${ }^{39}$ la fabricación de herramientas, el uso del lenguaje simbólico y la predominancia del hemisferio izquierdo son capacidades y características engarzadas que emergieron durante la escisión humana de los simios hace unos dos y medio millones de años. ${ }^{40}$ La temprana y complementaria división de labores de las dos manos, necesaria para la fabricación y uso de herramientas se acompañó de una especialización hemisférica, pues cada lado del cuerpo está controlado y es percibido por el hemisferio contrario del cerebro. Dado que tanto el lenguaje como el uso de herramientas requieren movimientos finos y secuencialmente coordinados, fue ventajoso durante la evolución asociarlos en un solo hemisferio en razón de una superior capacidad motora temporal y secuencial, tanto en el sentido de control como de velocidad de procesamiento. La hipótesis más atractiva de esta notable y significativa asociación entre la pericia manual y la lingüística afirmaría que la gesticulación lateralizada que implicó preferentemente el uso de la mano diestra se asoció a la simbolización verbal en el hemisferio contralateral. ${ }^{41}$ La liga explica por qué los individuos gesticulan más con su mano derecha al hablar y por qué la afasia de Broca casi siempre se acompaña de parálisis del brazo derecho. La decisiva coalición funcional probablemente involucró a las llamadas neuronas espejo que se activan al realizar un movimiento o al observar a otros realizarlo y que fueron detectadas originalmente en primates en zonas similares al área de Broca en los humanos. ${ }^{42}$

Además de la neurología, la lingüística ha venido a enriquecer el panorama de la neurobiología del lenguaje. Hacia mediados del siglo XX el conocido lingüista y politólogo de afinidad libertaria Noam Chomsky, uno de los patriarcas más celebrados de las ciencias cognitivas, fortaleció la teoría de Wilhelm von Humboldt, nombrado padre de la teoría lingüística, ${ }^{43}$ de una gramática universal, al considerar que bajo toda frase proferida existe una abstracción formal relacionada con su sentido. Todas las lenguas poseerían un núcleo común, una estructura profunda conformada en un dispositivo cerebral de organización innata, adquirido durante la evolución de los homínidos. Este nativismo implica módulos cerebrales especializados y se apoya en evidencias de que las funciones del lenguaje están procesadas en módulos como el área de Broca o el área de Wernike. ${ }^{44}$ Sin embargo, hoy sabemos que

39 La redundancia semántica es significativa de la lateralización.

40 Marietta Papadatou-Pastou (2011) Handedness and language lateralization: why are we right-handed and left-brained? Hellenic Journal of Psychology, Vol. 8, pp. 248-265

${ }^{41}$ Tanto los gestos de los iconos propios de la oratoria cristiana como los mudras de la tradición budista muestran posiciones retóricas de la mano derecha con significados bien establecidos en cada tradición.

${ }^{42}$ Rizzolatti G., Arbibi M.A. (1998). Language within our grasp. Trends in Neurosciences 22(4)151-152.

43 Wilhelm von Humboldt. Escritos sobre el lenguaje. Edición y traducción de Andrés Sánchez Pascual. Prólogo de José María Velarde. Ediciones Península 1999. Carmen Galán Rodríguez afirma que los conceptos de Humboldt de

"forma interna" y "enérgeia" han venido a considerarse claves en la lingüística moderna (file:///C:/Users/Dr\%20Diaz/Downloads/Dialnet-LaTeoriaLinguisticaDeWilhelmVonHumboldt-58813.pdf).

${ }_{44}$ Chomsky, Noam (2003) Sobre la naturaleza y el lenguaje. Traducción de Cristina Piña Aldao. México: Ediciones AKAL. 
la modularidad parcial de funciones mentales como el lenguaje ciertamente existe, pero se ve rebasada por el enlace y la integración de las funciones necesarias para la conciencia, el conocimiento y el significado.

Steven Pinker, célebre psicólogo de Harvard, ha empujado el innatismo naturalista de Chomsky en su libro El instinto del lenguaje al proponer que la teoría evolutiva provee una explicación causal del lenguaje, pues éste fue seleccionado por y para resolver problemas de comunicación. ${ }^{45}$ El lenguaje no sería una forma de tecnología semejante al uso de herramientas, sino una adaptación biológica, como el sonar de los delfines o como las telarañas, lo cual es verosímil pero incompleto, pues un determinismo genético de este tipo minimiza los factores sociales y culturales de la comunicación en el largo trayecto de los humanos. Un colaborador de Chomsky, el filósofo del lenguaje Jerry Fodor, elaboró una hipótesis central para la ciencia cognitiva inicial: el pensamiento entendido como procedimiento de tipo computacional que opera sobre representaciones simbólicas. Habría así un lenguaje universal y propio del pensamiento, que bautiza como mentalés, un sistema de representaciones simbólicas que ocurre en el cerebro y que explicaría la habilidad para comprender, procesar o engendrar frases nunca antes oídas o pronunciadas, ${ }^{46}$ una de las propiedades más espectaculares de la capacidad lingüística de los humanos.

Estas teorías concuerdan con la antigua idea racionalista tan ligada a Kant de que la mente no nace vacía de contenidos ni capta al mundo como una tabula rasa, sino que viene equipada con programas o tendencias que la psicología evolutiva ha considerado como moldeadoras de la cognición humana en forma general. Sin necesidad de excederse con estas nociones, se puede rescatar la idea de que los humanos vienen al mundo dotados de programas de dominio específico que son dependientes de contexto y están especializados para resolver problemas que enfrentaron nuestros ancestros arcaicos. Si bien parece aceptable la idea de que ciertas conductas y saberes semejan dotaciones de la especie humana, una pregunta más difícil de resolver es si existen símbolos concretos de origen ancestral o arquetipos que codifiquen o favorezcan contenidos que se expresen con los ornamentos de la lengua, la representación estética y las culturas particulares de grupos e individuos.

Muchos de los programas universales de la lengua operan de manera inconsciente y es probable que se encuentren codificados de manera laxa pero efectiva en redes neuronales de antigua adquisición. Los procesos mentales conscientes y explícitos descansan sobre un andamio de procesos arcaicos que el prominente neurólogo Antonio

45 Steven Pinker (2012) El instinto del lenguaje. Traducción de José Manuel Igoa y Alejandro Pradera. Madrid: Alianza Editorial.

46 Jerry A. Fodor (1985). El lenguaje del pensamiento. Madrid: Alianza Editorial. Véase también la evaluación del significado desde la psicología actual en "La sonrisa del gato de Cheshire y el concepto del significado en psicología" de Víctor Manuel Alcaraz Verduzco. En: Una mirada múltiple sobre el lenguaje (Víctor Manuel Alcaraz, coordinador), pp 241-270. Guadalajara, México: Universidad de Guadalajara.
Damasio considera como el núcleo de la conciencia. ${ }^{47}$ Es así que la imaginería emocional de los mitos, los sueños o las alucinaciones se ha atribuido a una fisiología cerebral más profunda y de adquisición más antigua que las partes de la neocorteza que fundamentan la racionalidad humana. ${ }^{48}$ Estas aportaciones teóricas están sujetas a revisión y ajuste por parte de la neurociencia cognitiva, pues ha ocurrido un desarrollo espectacular de técnicas para la exploración cerebral en sujetos humanos que realizan tareas cognitivas cuidadosamente calibradas. Entre esas técnicas destacan las imágenes cerebrales tanto eléctricas como metabólicas. Vale la pena referir algunas investigaciones relevantes al procesamiento del lenguaje realizadas con estos medios.

La investigación neurocognitiva reciente parece esclarecer algunas características del significado. Por ejemplo, la disyuntiva entre quienes consideraban que el significado de una palabra está en una imagen mental coligada a ella y quienes proponían que se trata de una abstracción puramente lingüística puede comprenderse mejor por el llamado efecto de concreción. Éste se refiere a toda diferencia conductual y neurofisiológica relacionada con el procesamiento de palabras en función del grado de concreción o imaginabilidad de sus significados. El efecto se manifiesta en mayor rapidez (menor tiempo de reacción) y mayor precisión (menor número de errores) al procesar palabras concretas que prontamente evocan imágenes. De esta manera existe un gradiente de concreción desde los términos que se asocian a imágenes hasta los más abstractos. Por otra parte, las palabras con significado comprensible evocan potenciales auditivos más complejos en el cerebro que las palabras sin sentido y esto es notable en una deflexión del potencial provocado que ocurre hacia los 400 milisegundos de presentada la palabra. Este potencial llamado N400 se asocia a la captación del significado de la palabra, se registra con mayor dimensión en las zonas del lenguaje y es de mayor amplitud para las palabras concretas que para las abstractas. ${ }^{49}$

En un ingenioso estudio del fascinante fenómeno de "punta de la lengua" mediante tomografía electromagnética del cerebro, los psicofisiólogos de la Universidad de Santiago de Compostela encontraron que es necesaria la activación secuencial de una red de áreas temporales posteriores y mediales, la ínsula y áreas prefrontales para la recuperación exitosa del nombre de personajes famosos presentados en una serie de fotografías. Cuando el sujeto reconoce a la persona pero no recuerda su nombre y refiere el estado de "punta de

\footnotetext{
${ }^{47}$ Antonio Damasio (2000) Sentir lo que sucede. Santiago: Editorial Andrés Bello. ${ }^{48}$ Erik D. Goodwyn (2012) The Neurobiology of the Gods: How Brain Physiolo gy Shapes the Recurrent Imagery of Myth and Dreams. New York: Routledge. 49 José María Ruiz-Vargas e lsabel Cuevas (1994) Imágenes mentales y memoria: hacia una explicación del efecto de concreción. Cognitiva 01/1994. $6(1): 3-25$. DOl: 10.1174/021435594321237810. Una amplia evaluación de los potenciales evocados en el estudio del lenguaje se encuentra en: Harmony Baillet, T., Silva Pereyra, J. (2000) Estudio del lenguaje por medio de los potenciales relacionados a eventos. En: Una mirada múltiple sobre el lenguaje (Víctor Manuel Alcaraz, coordinador), pp 271-295. Guadalajara, Mexico: Universidad de Guadalajara. La figura 20 está tomada de: Castro Salas, M. A. Potenciales Relacionados con Eventos (PREs) durante la percepción de palabras abstractas y concretas. Tesis de Maestría, Instituto de Neurociencias. Universidad de Guadalajara, 2008.
} 
la lengua" esta red no se activa en todos sus nodos ni en la secuencia adecuada. La búsqueda continua del nombre por más de un segundo implica la actividad del cíngulo anterior y una red frontal involucrada en la memoria semántica. ${ }^{50}$

En otro tipo de experimentos, se ha detectado que existen neuronas situadas en el lóbulo temporal que responden a los nombres de personas y cosas particulares. A finales del siglo XIX William James las predijo teóricamente con el patriarcal nombre de "células pontificales" y luego fueron llamadas "neuronas gnósticas". Sucede que estas células responden no sólo al nombre de una persona conocida, sino a sus diversas imágenes, poses o personajes que interprete. Se ha llamado "neurona Marilyn Monroe", a la célula que se activa al ver imágenes diversas de la diva, incluso cuando se le reconoce de espaldas, pero también al oír o leer su nombre. ${ }^{51}$ A pesar de lo sensacional del hallazgo, no se debe concluir que el concepto, la representación o el significado residen en una neurona, pero sí que ésta es un nodo crucial de una red genéticamente dispuesta, pero que se acondiciona por aprendizaje repetitivo para procesar información sobre una persona o un objeto, ligada centralmente al concepto.

Se ha averiguado también que los verbos y los sustantivos activan diferentes zonas del cerebro. Los verbos que implican acciones encienden zonas frontales cercanas a las regiones motoras que guían el movimiento, en tanto que los sustantivos que designan objetos activan la corteza del lóbulo temporal entre las regiones de la audición y la visión y que son cruciales para identificar qué es lo que se oye o se mira. Un grupo de investigadores rusos ${ }^{52}$ reportó el mes de abril de 2014 que los verbos y nombres que implican acciones como saltar, lanzar, patada o baile inducen la actividad de la porción de la corteza motora implicada específicamente por el significado de estas palabras: la zona de la pierna. Esto sucede a los 80 milisegundos de escuchar o leer las palabras, mucho antes de que el sujeto capte el significado, lo cual, como ya vimos, ocurre después de 300 milisegundos. Este proceso constituye un fundamento neural de la semántica, pues los circuitos motores específicos están comprometidos en el significado de estas palabras de manera automática. De manera congruente con esto, un grupo de neurocientíficos británicos ha visualizado los cerebros de 12 voluntarios sanos cuando escuchan frases comunes, chistes o juegos de palabras. Observaron que las zonas de recompensa se activan de manera mucho más intensa con chistes o juegos de palabras que con frases comunes y la respuesta es proporcional a lo divertido que los sujetos encuentran cada uno de los chistes. ${ }^{53}$

\footnotetext{
50 Santiago Galdo-Álvarez, Mónica Lindín y Fernando Díaz (201 1) Brain dinamics associated with face-naming and the tip-of-the-tongue state. Psicothema 23 (2): $189-195$.

R. Quian Quiroga, L. Reddy, G. Kreiman, C. Koch. Invariant visual representation by single neurons in the human brain (2005) Nature 435, $1102-1107$. doi: 10.1038/nature03687

52 Yury Shtyrova, Anna Butorinad, Anastasia Nikolaevad, Tatiana Stroganovad (2014) Automatic ultrarapid activation and inhibition of cortical motor syste$\mathrm{ms}$ in spoken word comprehension. Proceedings of the National Academy of $\mathrm{ms}$ in spoken word comprehension. Proceeding
Sciences. doi: 10.1073/pnas.1323158111.

${ }_{53}$ Mobbs, D., Greicius, A., Eiman, M. V., Reiss, A.L. (2003) Humor Modulates the Mesolimbic Reward Centers. Neuron 40 (5): $1041-1048$.
}

Durante un estudio de resonancia magnética funcional ${ }^{54}$ 15 voluntarios cristianos y 15 no creyentes, se pronunciaron sobre la verdad o falsedad de locuciones tanto religiosas (ejemplo: "los ángeles existen") como no religiosas ("Alejandro Magno fue un famoso caudillo militar"). Las imágenes cerebrales de los creyentes y no creyentes eran indistinguibles, lo que sugiere que la evaluación de verdad o falsedad es independiente de su contenido. Si bien desde un punto de vista fenomenológico y semántico es muy distinto creer que los ángeles existen y que Alejandro Magno fue un gran guerrero, por el momento en el cerebro no se distingue más que el acto de creer y no el contenido. Otros experimentos han mostrado que las mismas áreas cerebrales se activan durante el procesamiento de frases tanto literales como metafóricas, en tanto que la conciencia cualitativa de uno y otro es claramente distinta. ${ }^{55}$ Como puede verse, queda mucho por conocer respecto a las diferencias en los contenidos de las locuciones y creencias, es decir el contenido de las representaciones mentales, pero ya sabemos que el significado no se asocia a la actividad de un módulo, sino que engancha a las zonas del cerebro cuyas funciones están aludidas por la palabra o el enunciado. Es así que el significado se basa en funciones primarias del cuerpo y su cerebro, pero ¿en qué consiste y cómo ocurre la representación?

\section{REPRESENTACIÓN Y SIGNIFICADO}

Los neurofisiólogos utilizan el concepto de representación para referirse a las neuronas o sectores nerviosos que se activan durante la ejecución de una tarea cognitiva específica y en particular a las pautas espaciotemporales de actividad eléctrica de las neuronas que de esa manera codifican y transmiten contenidos de información. ${ }^{56}$ Es permisible suponer que estos códigos de actividad nerviosa se constituyen en procesamientos cognitivos de información porque son la base de una pirámide que incluye niveles crecientes de organización en redes, módulos y actividades intermodulares en el cerebro entero y se corresponden con niveles de elaboración cognitiva. En ese escalafón se puede postular la emergencia de representaciones simbólicas a partir de las representaciones neurofisiológicas y plantear una correlación entre procesos conscientes y procesos cerebrales de alto nivel de integración, en tanto constituyen dos aspectos de un procedimiento de naturaleza psicofísica. ${ }^{57}$ Las representaciones mentales están entonces enraizadas en niveles de organización, desde los más básicos correspondientes a las

54 Harris S., Kaplan J.T., Curiel A., Bookheimer S.Y., lacoboni M. (2009) The Neural 'Correlates of Religious and Nonreligious Belief. PLoS ONE 5(1): 10.1371/annotation/7fOb 174d-ab93-4844-8305-1 de22836aab8.

55 Véase el artículo "This Is Your Brain on Metaphors" de Robert Sapolsky en el

New York Times del 14 de noviembre de 2010.

56 Para la neurofisiología, la actividad eléctrica de las neuronas constituye "el lenguaje del cerebro"; véase como ejemplo: Lenguajes del cerebro de José $M$. Delgado García, Editorial Letra Áurea, 2006

57 J.L. Díaz (2007) La conciencia viviente. México: Fondo de Cultura Económica. 
proyecciones sensoriales de los objetos del mundo, pasando por un nivel intermedio de representaciones categóricas aprendidas de rasgos invariantes de objetos, hasta un nivel integrado y emergente de representaciones superiores propiamente simbólicas y semánticas. De esta manera se puede plantear la siguiente hipótesis neurosemántica: la representación nerviosa se basa en códigos de disparo de neuronas que se organizan de manera compleja en redes, que el contenido está determinado por el origen y destino de las vías entre los diversos módulos del cerebro y finalmente que el significado está definido por la pauta dinámica de las interconexiones entre los módulos, todo ello en asociación íntima con los sistemas perceptivos y motores del cuerpo. ${ }^{58}$

La hipótesis del enjambre ${ }^{59}$ propone que la dinámica intermodular del cerebro es necesaria para la conciencia y para el significado pues es un proceso super-organizado de activación espaciotemporal y, por ello, en analogía como los enjambres de insectos y las parvadas de pájaros, es apto para navegar, pulular, girar, escindirse o afluir a través del encéfalo y enlazar sus diversos subsistemas de forma veloz y efectiva para constituir "bulliciosas colmenas", según la elocuente metáfora del pionero de la neurociencia moderna, el sabio español Santiago Ramón y Cajal. En concordancia con esta propiedad, el procesamiento consciente es capaz de acceder, coordinar e integrar múltiples mecanismos locales de información, como sucede, por ejemplo, cuando en un recuerdo se unifican una imagen mental, un pensamiento y una emoción, operaciones segregadas en distintos substratos y módulos nerviosos que se reúnen en un sólo contenido y proceso, es decir, en una experiencia consciente.

El proceso consciente es el aspecto mental del desempeño neurológico del más alto nivel de integración, un fenómeno con plenas capacidades causales sobre el funcionamiento de los sistemas de menor jerarquía que moldean el habla y la expresión de la conducta en general. Por añadidura, esta capacidad expresiva de los sistemas conscientes por medio del lenguaje y la acción del individuo tiene efectos diversos y potencialmente trascendentes sobre el sistema social y cultural. Esto es patente para las actividades creativas que se producen como un procesamiento consciente y luego se plasman o expresan mediante actos, símbolos, teorías científicas, productos de arte o técnica hacia el medio social, cultural y ecológico.

Las pautas físicas externas, como el lenguaje oral o escrito, la música o el imaginario social que incluye a las artes plásticas, constituyen códigos de información transcendentes que rebasan a los sujetos para perdurar o desplazarse en tiempo y espacio. Estas pautas se pueden concebir como homólogas con las operaciones cerebrales que las asimilan, transforman o expresan, lo cual es la base de la teoría de procesos pautados. ${ }^{60}$ Tales procesos, entre los que destacan el flujo de conectividad

58 Véase Díaz (op cit. 2007: 436-443) y la introducción del libro de S. W. Kuffler y J.G. Nicholls (1976) From Neuron to Brain. Sinauer Associates, Suberland.

59 Díaz, op cit (2007: 445-474)

60 Díaz, op cit (2007, capítulo XI) del cerebro, la secuencia de actos que conforman la expresión de conducta o el procesamiento de elementos mentales que caracterizan a la conciencia, serían transformaciones de información que permean entre los sistemas sociales y neurobiológicos para lograr y compartir operaciones cognitivas. Esas pautas no pueden ser físicamente idénticas en su transcurso por los diversos medios de soporte y la información acarreada utiliza múltiples canales y sufre transformaciones entre los sistemas biológicos, los nichos ambientales y las expresiones sociales. Este intercambio de información mental ocurre gracias a la conducta y los sistemas sensitivo-motores, piezas cruciales situadas entre el cerebro y el mundo.

Los elementos en transición de estos procesos pautados tienen una arquitectura narrativa y cinemática definida por unidades (notas, palabras, actos) que ocurren en ciertas secuencias (melodías, frases, actividades), combinaciones (armonías, fusiones gesto-palabra), ritmos (cadencias, acentos) y cualidades (timbres, connotaciones). Se trata de formas en movimiento que se despliegan en el tiempo con una probabilidad de transición semiordenanda o estocástica, con una intrincada periodicidad rítmica, con una amplia combinación de unidades y con un factor cualitativo de modalidades particulares de cada proceso definido, como son las cualidades de la conciencia. El caso de la música es paradigmático de un proceso pautado pues incide en la función nerviosa para permitir la emoción y la figuración musical por la correspondencia entre las estructuras ondulatorias espaciotemporales de una ordenación sonora y ciertas estructuras espaciotemporales del procesamiento cerebral mediadas por la conducta para producir el sonido y por el sistema auditivo para percibirlo. De esta manera, la música no sólo sería una expresión creativa propia de ciertas actividades mentales afectivas y figurativas, sino esencialmente una formación sonora externa complementaria de una emoción o figuración interna la cual adquiere una "forma" musical que, al interpretarse, se esparce por el medio elástico del aire como prolongación de ciertos circuitos y procesos cerebrales permitiendo que cierta emoción musical se comparta entre el compositor, el intérprete y el escucha. Los efectos emocionales de la música requieren así de mecanismos simbólicos de alta jerarquía del cerebro funcionando o resonando al unísono con cosmovisiones y pautas culturales.

\section{EL LOGOS RECOBRADO}

El filósofo hispano-mexicano Eduardo Nicol rescató y actualizó el Logos de Heráclito como el ámbito simbólico humano y argumentó robustamente que no es una capacidad privada y hermética, sino, al contrario, está a la vista en el mundo de la cultura. En La metafísica de la expresión, de 1957, rescató la función simbólica como la esencia de la expresión y a su comunicación entre seres humanos como el mecanismo vinculante de la cultura. ${ }^{61}$

${ }^{61}$ Eduardo Nicol (1957) La metafísica de la expresión. México: Fondo de Cultura Económica. 
En este sentido hay que señalar que el proceso simbólico -el Logos, el Verbo- es un elemento común y natural a la cultura, a la conciencia y al cerebro y requiere ser explicado en términos de procesos cerebrales que alcanzan a detentar significados o símbolos. El símbolo externo o cultural es un estímulo dual en el sentido que codifica por un lado una liga con el objeto y por otro con el agente. Según el estructuralismo biogenético, ${ }^{62}$ el significado del símbolo está mediado por procesos culturales acoplados a procesos cerebrales mediante una práctica, de tal forma que los elementos complementarios serían, por un lado, un procesamiento cerebral particular y, por otro, una conducta desarrollada y aprendida en el medio cultural.

Algo desconocido y desconcertante unifica la mente y el cuerpo, la conciencia y el cerebro, el significado y el enjambre neuronal, algo que debe conformar una unidad, una realidad psicofísica que reta y ha esquivado de manera recalcitrante al entendimiento humano. Para conceptuar esta unidad es necesario considerar que la conciencia tiene una base o una raíz orgánica nerviosa sumamente peculiar ya que el cerebro genera esa propiedad natural alojando y manipulando el ambiente mediante las peculiaridades distintivas de este órgano maravilloso, el sistema que ostenta la red de comunicación más compleja que se conoce y cuya anatomía conectiva se intenta desentrañar en el magno proyecto del conectoma. ${ }^{63}$

El reto es formidable, pues los eventos mentales conscientes, como los significados, poseen una naturaleza fenomenológica y subjetiva que difiere drásticamente de los eventos electroquímicos que ocurren entre las neuronas. Esta brecha es el núcleo duro de roer del problema mente-cuerpo, pues aun si lográramos mediante un ingenioso cerebroscopio detectar las frases que piensa un sujeto al decodificar exitosamente sus correspondientes señales eléctricas en el cerebro, esto no constituiría una verdadera lectura de la mente y la experiencia, sino un vistazo indirecto y parcial de sus contenidos, entre los cuales quedarían excluidos el significado preciso de los vocablos para el sujeto pensativo y todo el cortejo cualitativo, intuitivo, emocional, prospectivo e intencional de su cavilación. En sus Cahiers de 1920, Paul Valery escribió: "estos pensamientos que escribo no son los pensamientos que tengo", lo cual quiere decir que el enunciado del pensamiento propio en forma de lenguaje natural restringe, disminuye o incluso traiciona al propio pensamiento tal y como fue sentido o experimentado, una idea apasionadamente expuesta por Rosalía de Castro en el epígrafe de esta conferencia.

Más aún: para traducir adecuadamente la actividad cerebral en actividad mental se necesitaría establecer una relación bi-unívoca entre un proceso mental y un proceso cerebral. ${ }^{64}$ Pero esto es improbable, pues los mismos actos

\footnotetext{
${ }^{62}$ Brain, Symbol and Experience. Toward a Neurophenomenology of Consciousness de Charles D. Laughlin, Eugene d'Aquili y John McManus (1993) New York: Columbia University Press.

${ }_{63}$ Sebastian Seung (2012) Connectome: How the Brain's Wiring Makes Us Who We Are. Houghton Mifflin Harcourt.

64 Donald Davidson (1980) Essays on Actions and Events. Oxford: Clarendon. Traducido al castellano por el Instituto de Investigaciones Filosóficas de la UNAM y editado en 1995 por la UNAM y por Critica con el título de Ensayos sobre acciones y sucesos.
}

mentales pueden ser ejecutados por diferentes redes neuronales como, a la inversa, la misma red puede, de acuerdo a variantes sinápticas o neuroquímicas determinadas por su historia, consumar diversos actos mentales, lo cual es muy patente en la recuperación de funciones perdidas por accidentes cerebro-vasculares. La cerebroscopía requeriría una forma insólita de hermenéutica, una técnica de interpretación que dependería crucialmente de que los significados de las señales cerebrales se encuentren debidamente establecidos. Además, para realizar la correlación, será inevitable recurrir al informe en primera persona del sujeto, que es el mecanismo tradicional para conocer la mente ajena y que, empleado ya por Homero, ha llegado a una cúspide expresiva en el monólogo interior desarrollado por novelistas como Virginia Wolf o James Joyce. ${ }^{65}$

En este punto solicito un último ejercicio mental por parte del oyente o lector de este texto y es que evoque ahora a su ancestro más querido... En mi caso particular, si pienso en mi querido abuelo Juan, un cabal campesino gallego llamado por sus hijos y nietos "Papá Juanito", no sólo vienen a la mente imágenes o escenas sensoriales, en especial visuales y auditivas ocurridas hace 60 o más años, sino que ocurren en vertiginosa asociación con ellas sentimientos, intenciones, fantasías y pensamientos en lenguaje interno, sea como voces de mi añorado abuelo o en forma de comentario paralelo a la experiencia por un Yo escurridizo. Una transcripción de las palabras que pasan por la mente sería un logro extraordinario, que quizás alcance parcialmente la neurociencia cognitiva del futuro, con todos los peligros que eso entrañaría, pero aún insuficiente para revelar la experiencia mental y el pletórico significado que la expresión "Papá Juanito" tiene para mí, o del personaje evocado por el lector o el oyente en la intimidad de su conciencia.

En este marco de evocación de mis mayores, concluyo con un colofón de cauto entusiasmo, valga el oxímoron. La contribución naciente de las ciencias biológicas, cognitivas y cerebrales coordinadas con las Humanidades para comprender la naturaleza de la lengua y el significado del significado es tan reveladora como desafiante. Lejos de reducir el Logos a conductas compartidas, a módulos cerebrales o a redes neuronales, enaltece la naturaleza de la lengua con evidencias neurológicas y con teorías cognitivas contrastables, dispone al Homo sapiens como Homo loquens entre las criaturas significantes de la Tierra, reconoce el magisterio de la poesía y salvaguarda la incógnita del símbolo y del significado como un reto colosal que requiere de la investigación más osada y creativa.

${ }^{65}$ Al respecto véase Díaz 2007 (Op. cit. capítulo XV) y Leer la mente de Jorge
Volpi (México: Alfaguara, 2011). 